\title{
DEVELOPMENT AND VALIDATION OF THE TEACHER LEADERSHIP COMPETENCY SCALE
}

\author{
${ }^{1}$ Fanny Kho Chee Yuet1, Hamidah Yusof \& \\ Syed Ismail Syed Mohamad \\ Faculty of Management and Economics \\ Universiti Pendidikan Sultan Idris, Malaysia \\ ${ }^{1}$ Corresponding author: fannykcy@gmail.com
}

\begin{abstract}
Purpose - The main purpose of the study was to develop an empirically validated Teacher Leadership Competency Model (TLCM) which would enhance teacher leadership competencies in Malaysian secondary schools. There is currently no established instrument that measures teacher leadership competency, particularly in the Malaysian context.
\end{abstract}

Methodology -Structural equation modeling (SEM) utilizing AMOS Version 22 was employed to develop the model. Exploratory factor analysis was utilized to identify the underlying factors, whereas confirmatory factor analysis was employed to test the construct of the TLCM. The study particularly targeted a total of 928 trained teachers from 58 high-performing secondary schools in Malaysia. It explored their perception of the notion of teacher leadership competencies and their commitment to change their initial role as classroom leaders to teacher leaders in their respective schools.

Findings - The Teacher Leadership Competency Model (TLCM) was found to be a fit and reliable model with all fit statistics set well above the threshold level. The Teacher Leadership Competency Scale (TLCS), which comprised 21 items, would also benefit school principals in assessing the effectiveness of teacher leadership and teacher commitment in assuming new leadership roles in school change initiatives. The finding has also encouraged a fresh look at the implementation of teacher leadership programmes aimed at successful change in schools. 
Significance - This study has pioneered research in the measurement of teacher leadership competency, the first of its kind, in the Malaysian context. Teacher leadership is a critical component in shifting the paradigm of teacher isolation to one of collaboration in the Malaysian school context. The findings of the TLCM will also benefit educational practitioners in designing a Teacher Education Model for Malaysia.

Keywords: Teacher Leadership Competency, Structural Equation Modeling, Exploratory Factor Analysis, Confirmatory Factor Analysis, Developmental Leadership Behavior of Principals, Teacher Commitment to Change.

\section{INTRODUCTION}

Leadership is a commonly utilized word with a multitude of definitions applicable to distinct individuals. It always serves the interests of those who become, or choose to be followers. Learning too is a commonsensical terminology. Leadership roles, for instance, are assumed in daily exchanges between parents and children, as well as teachers and students in daily classroom instructional practices. The children and students will have to do what they have been told. Simply stated, learning about leadership is all around us and in every action we take.

Yet, one may fail to perceive ways in which leadership and learning are interconnected, i.e., if we fail to gain new insights into the meanings of these two commonsensical terminologies. Insight refers to the act of taking a new look, a new way of seeing, and a new way of knowing. In other words, we must learn to know what we see rather than seeing what we already know (Heschel, 1962). Educators, for instance, need to take a second look at what they believe to be true, which take into consideration two complementary elements, i.e., the conceptual and the practical. Therefore, teachers need to bring their conceptual knowledge and practical knowledge closer together. In other words, they need to carefully identify structures and routines that do not really help and in contrast, contribute to constraint in learning among children, which in turn, also inhibit the learning of those who teach and lead them. Thus, this is where leadership 
comes into its own (Kho, F.C.Y., Hamidah Yusof, \& Syed Ismail Syed Mohamad, 2015).

Leadership is strengthened when it takes into consideration the three linear but fundamentally essential ideas, i.e., connect, extend, and challenge (MacBeath, 2012). In schools, the true measure of leadership for learning will highly depend on the effectiveness of leadership in the classrooms. All of what teachers do in a classroom is infused with knowing and feeling. They must be able to connect with what is already known and connect them with what children know and bring them into the classroom, namely prior knowledge, prior feelings, prior skills and expertise. Likewise, teaching requires teachers to extend their knowledge and their repertoire of skills. As they become competent and more skilful practitioners, they have a moral and professional obligation to challenge their practice and to be open to new challenges.

This is supported by the work of Andrews, Crowther, Hann and McMaster (2002: 25) who have developed a "Teachers As Leaders" framework which highlights the importance of two key factors determining the leadership of teachers, namely the valuesbased and power-based of their instructional practices, and their abilities to create new meaning in the lives of people in schools and communities. The researchers also made an important distinction between teachers as leaders in a specialized area, such as pedagogical leadership and (subject) discipline leadership and leadership which contributes to whole school reform and improvement. This focus on school improvement was central to the recent Federal Government trial project of a shared leadership approach in schools in Australia (Chesterton \& Duignan, 2004).

In fact, the norm of such a shared approach to leadership requires teachers to take on leadership responsibilities 'in parallel' with the principal and the executive, within a whole school improvement framework (Crowther, F., Kaagan, S., Ferguson, M., \& Hann, L., 2002a\& 2002b). Similarly, Lashway (2003), Pearce and Sims (2002), Harris (2002), Spillane, Halverson and Diamond, (2001), and Elmore (2000) have explored the nature of shared leadership which was widely distributed across key stakeholders, especially teachers. 
Elmore (2000), too, argued that leadership of schools was beyond the capacity of any one person and needed to be 'distributed' to incorporate the contours of expertise within a culture that provided coherence, guidance and direction for instructional practice. Elmore (2000), cautioned, however, that collaborative work by teachers would not, alone, lead to changed teacher practices and improved learning among students. He believed that to engage teachers productively in leadership there had to be a whole-school focus on change and improvement.

Indeed, leading change from the classroom was closely linked with the development of teacher leaders (Kho et al., 2015). Development of teacher leaders was considered to be the significant outcome of teacher commitment to change from the classrooms. In this regard, it was a privilege for teacher leaders to walk with principals who portrayed developmental leadership behaviors in order to be competent teacher leaders (Khoet al., 2015). In general, teacher leaders therefore need to understand exactly what they are leading, clearly communicate their intentions for teacher leadership, while actively building connections, coherence and alignment across teacher leadership behaviours throughout the classroom. This alignment was best achieved through identifying a few clear priorities for teacher leadership in enhancing student academic performance and ensuring that these were embraced, embedded and reinforced (Fullan, 2010).

With respect to school improvement and change, Harris (2002, p.2) argued that there was an extensive body of research, which had supported the claim that strong collegial relationship, mutual trust, support and a focus on enquiry were crucial for effective improvement. There was evidence to suggest that student outcomes were more likely to improve where leadership sources were distributed throughout the school and where teachers were empowered in decision-making related to instructional practices and assessment (Silins \& Mulford, 2002; Norazlinda Saad \& Surendran Sankaran, 2013). When teachers were involved in the decision-making process, they obtained professional satisfaction (Abdulhakam Hengpiya, 2008). 


\section{The Elements of Teacher Leadership Competency (TLC)}

The Teacher Leadership Competency Model (TLCM) in the current study was constructed based on four different types of models which had guided teacher leadership development in schools (Kho et al., 2015). These models include: i) The Framework for Teaching Evaluation Instrument (Danielson, 2013), ii) Teacher Leadership Framework (Centre for Strengthening Teaching Profession, 2009), iii) Teachers as Leaders Framework (Crowther, 2008), and iv) Teacher Leader Model Standards (Teacher Leadership Exploratory Consortium, 2011). The latter serve as the core model in this study. The Teacher Leadership Competency Model(TLCM) proposed in this study encompassed five main elements: i) Facilitating Improvement and Establishing Standards; ii) Modeling Leadership Attributes and Skills; iii) Participating in Organizational Development; iv) Fostering a Collaborative Culture; and v) Performing as Referral Leader.

Facilitating Improvement and Establishing Standards (FIES) had emphasized the improvement of teacher instructional practices while taking into consideration diverse student learning needs. Indeed, pedagogical excellence was seen as concerned with both pedagogical and social nature, and thus, teacher leaders needed both competencies in order to influence student engagement beyond the classroom (Katyal \& Evers, 2004). It was constructed based on the third role of teacher leaders - 'Strive for pedagogical excellence'.

Modeling Leadership Attributes and Skills (MLAS) had focused on common leadership values, leadership knowledge and leadership skills required by teacher leaders in order to lead. It was constructed based upon teacher leadership definition by the Centre for Strengthening the Teaching Profession (2009). The centre also defined teacher leadership as 'knowledge, skills and dispositions' portrayed by teachers who positively impacted students' learning by influencing them, formally and informally, beyond individual classrooms.

Participating in Organizational Development (POD) was concerned with involving teachers in school change initiatives, teachers assisting principals to manage and administrate the school, and 
teachers utilizing relevant data in decision-making (Norazlinda Saad \& Surendran Sankaran, 2013). It was constructed based on the fifth domain in the Teacher Leader Model Standards (Teacher Leadership Exploratory Consortium, 2011). This domain was addressed as 'Promoting the Use of Assessments and Data for School and District Improvement'. Leadership expert, Spillane (2006) claimed that leaders needed to participate in the core work of the administration competently. In line with this, teacher leaders should have the competency to assist their principals or colleagues in utilizing multiple assessment tools which were aligned to state and local standards, particularly in the school change process. In sum, it can be concluded that the 'school administration' should focused on getting teacher leaders to be the front-line personnel, who shared responsibilities with school administrators in order to run the schools and guide other colleagues towards achieving the school's vision.

Fostering a Collaborative Culture (FCC) was focused on nurturing life-long learning and fostering reflective practices in order to support teachers' collaboration and student learning, and to enhance knowledge and ideas with other educators from other learning institutions for the best results. It was identified based on the fourth domain of Danielson's Framework for Teaching Evaluation Instrument, which was 'Participating in the Professional Community'. According to Danielson (2013), teachers should work with their colleagues for the betterment of the school and getting involved in the 'professional community'. Principals, on the other hand, should harness their leadership skills and appoint competent teacher leaders who have the leadership values, knowledge and skills, to successfully lead their colleagues towards achieving school goals. In other words, a professional learning community could be developed via teacher leadership (Barth, 2001).

Performing as Referral Leader (PRL) was focused on teacher leaders becoming referral leaders and this would be reflected in their own willingness to go beyond their own prescribed roles. These referral leaders would have impact in the area of their expertise and by demonstrating high ethical standards would be able to realize change initiatives in Malaysian schools. It was identified based on the Teachers as Leaders Framework (Crowther, 2008). According 
to Knapp et al. (2003), teacher leadership was "the act of imparting purpose to an organization as well as motivating and sustaining effort in pursuit of that purpose" (p.13). Thus, teacher leaders needed to continuously polish their talents as 'instructional experts', to enable them to guide their colleagues in overcoming instructional issues and making informed decisions that improve learning for all students (Norazlinda Saad \& Surendran Sankaran, 2013).

\section{METHODOLOGY}

Basically, the research design of the study employed the hypotheticodeductive method. It was articulated by the deductivist, Popper (1970). In essence, it illustrates the step-by-step process that needs to be undertaken for the study. The Teacher Leadership Competency Scale (TLCS) utilized in the study was developed and adapted based on concepts derived from diverse fields (Kho et al., 2015). The instrument then underwent pilot tests procedures for validation purposes. For sampling procedures, multiple-staged stratified random sampling was employed in this study due to its highly recommended efficiency (Sekaran, 2000).

\section{Population and Sample}

The ideal population of the study consisted of all the trained teachers in all secondary schools in Malaysia $(\mathrm{N}=182,408)$. The research population was drawn from 16,892 High Performing Secondary Schools (HPSS) in Malaysia (KPM, 2014). The HPSS and their teachers were the sites and study population chosen for the study as they were 'information rich' and of central importance to the purpose of the study (Patton, 2002). With 58 schools identified, 16 teacher respondents from each of these schools were chosen as the sample by using the simple random sampling method on the official list of teachers provided by the State Education Departments. As a result, 352 teachers were selected to represent DSS, 368 for FRSS and 208 for RSS. Overall, a total number of 928 respondents were identified for the survey and this constituted $25 \%$ of the total number of teachers in the 58 HPSS ( $\mathrm{N}=3,665)$ (Khoet al., 2015). Importantly, it meets the basic requirement of evaluating the overall fit of the hypothesized models using Structural Equation Modeling 
(SEM) analysis (Byrne, 2001; Chua, 2009; Kline, 2005). Basically, the researcher can more accurately identify the TLC regardless of school performance and student achievements, as well as school reform.

\section{Survey}

The current study adopted a quantitative approach which utilized the survey method as a data collection procedure. Creswell (2005) has offered additional insights by pointing out that quantitative research should establish the overall tendency of responses from individuals and to also note a great number of population views on an issue, as well as the diversity in these views through objective values. In order to minimize the potential for measurement error as well as to validate the soundness of the data, the basic procedures of data cleaning and screening were employed. Descriptive statistical procedures were used to analyze the preliminary data. Structural Equation Modeling (SEM) was employed in order to assess the measurement model. The study hence adopted a quantitative approach. This approach develops valid and reliable strategies of collecting factual information and opinions concerning teacher leadership competencies. In other words, the survey questionnaire utilized in the current study can provide some insight into individual perceptions (Baruch \& Holtom, 2008). Hence, a self-administered questionnaire was constructed (Kho et al., 2015).

\section{Pilot Study}

The Teacher Leadership Competencies Scale (TLCS) developed for this study had undergone an evaluation process before its final administration (Kho et al., 2014, 2015, 2015a; Nor Asma Sheirnawani Abdul Rahman, 2014; Fink, 2006; Creswell, 2005; Sekaran, 2003; Saunders, Lewis \& Thornbill, 1997). A pilot study is regarded a significant approach in ensuring the reliability and validity of the instrument, and its adequacy (Saunders et al., 1997). Ambiguous items will be dropped in order to determine the validity and reliability of the research instrument (Johnson \& Christensen, 2008). Six distinct approaches were applied to ensure the validity and reliability of the instrument in the study (Kho et al., 2015). First, the TLCS was initially peer reviewed by the members and supervisors 
of the Niche-Research Grant Scheme (NRGS) research team, as was recommended by the educational experts, Netemeyer, Bearden, and Sharma (2003). The peer reviewed was particularly needed as the items were self-developed by the researcher and the research team members (Kho et al., 2015). Second, seven face-to-face discussions with the research team members and supervisors were carried out respectively (Khoet al., 2015). In fact, each subsequent instrument was constructed based on the preceding instrument. Some of the items were modified and redrafted based on the outcome of each discussion so as to ensure their precision and clarity.

Third, the original instrument which was prepared in English were then translated into Malay. This was because most of the population sample was non-English speakers. The instrument then underwent a back-translation process. This process was significantly important (Frazer \& Lawley, 2000) as it would enable the respondents to give their genuine responses, and to avoid cultural differences which may confound the results (Salciuviene, Auruskeviciene, \& Lydeka, 2005). Fourth, three personal interviews were conducted (Bowen \&Shoemake, 1998) upon completion of the instrument. The purpose of these interviews was to identify any problems pertaining to the format, syntax, design, and allocation of time to complete the instrument. Besides, the participants were also given the opportunity to provide constructive comments or suggestions on ways to improve the instrument. The instrument was then being modified based on the comments or suggestions received (Kho et al., 2015).

Fifth, the instrument was distributed to seven research team members, whose task was to evaluate the clarity of each item (Flowers, 2006) based on the scale of 1 to 10 . This step was aimed at determining the validity coefficient for each item and whether the instrument was actually interpreted in the way it was designed specifically for the target population. Obviously, as illustrated in Table 1, all items in each domain yielded a high average score for clarity with at least 9.13 and the average score for the TLC was 9.50. Simply stated, all the 31 items were considered as high in content validity.

Sixth, a pilot field-test was also conducted in order to assess the internal consistency reliability (Cronbach's alpha), and the consistency of 
the instrument across all the items under each construct (Neuman, 2006). Low values of alpha would indicate that the items captured the construct poorly (Churchill, 1995). The threshold for this study was set at 0.75 . Cronbach's alpha and item-scales for the TLCS were calculated separately based on each construct. As all the 31 items for the TLCS were compliant with the statistical requirements, i.e., the Cronbach alpha was .977, Cronbach for the five constructs of the TLC ranges from .902 to .939 , and the item-scale for all items met the threshold of more than 0.7 (Cronbach, 1951). Therefore, all the 31 items were retained. The Cronbach alpha obtained implied that the overall reliability for the TLCS was very high.

Table 1

Item Clarity Average Scores of the TLC Domain and Construct

\begin{tabular}{llll}
\hline Domain & Construct & $\begin{array}{l}\text { Average } \\
\text { Score of the } \\
\text { Construct }\end{array}$ & $\begin{array}{l}\text { Average } \\
\text { Score of } \\
\text { the Domain }\end{array}$ \\
\hline $\begin{array}{l}\text { Teachers' } \\
\text { Leadership } \\
\text { Competencies }\end{array}$ & $\begin{array}{l}\text { Facilitating Improvement and } \\
\text { Establishing Standards } \\
\text { Modeling Leadership Attributes } \\
\text { and Skills }\end{array}$ & 9.81 & \\
& $\begin{array}{l}\text { Participating in Organizational } \\
\text { Development } \\
\text { Fostering a Collaborative Culture } \\
\end{array}$ & 9.38 & 9.73 \\
& $\begin{array}{l}\text { Performing as Referral Leader } \\
\text { Total Average Score }\end{array}$ & 9.46 & \\
& & & 9.50 \\
\hline
\end{tabular}

Seventh, an Exploratory Factor Analysis (EFA) was carried out to verify the conceptualization on the constructs and the dimensions of the TLCS. The EFA was employed for two major interrelated determinations. First, it was to identify the structure of the measurement model, and to summarize the items into each respective variable (Kline, 2005). Second, it was necessary to identify the contribution of each item to the factor, its so-called factor loading. This process was considered significant as it would make the data more parsimonious for subsequent multivariate analysis. Through this process, items with a low factor loading would be dropped in order to construct the main factor examined in the instrument (Hair, Black, Babin, Anderson \& Tatham, 2010). 


\section{Exploratory Factor Analysis on the TLCS}

It was found that iterations of the EFA were necessary until individual components were formed (Mahaliza Mansor, Norlia Mat Norwani \& Shahril @ Charil Marzuki, 2011). All the 31 items of the TLCS were manipulated to Principal Component Analysis (PCA) utilizing the Statistical Package for the Social Science (SPSS) Version 20.0 (Kho et al., 2015). Prior to operating the PCA, the fitness of data for factor analysis was determined. An investigation of the correlation matrix affirmed the existence of many coefficients of .5 and above. The communalities values with all values exceeding .5 indicated that the sample size was adequate (Hair et al., 2009). The Kaiser-Meyer-Oklin value was .930, which exceeded the recommended cutoff value of .6 (Kaiser, 1970, 1974). The Barlett's Test of Sphericity reached statistical significance, which was $p<.05$, supporting the factorability of the correlation matrix, and indicated that the correlation between items was acceptable to run the factor analysis.

Additionally, as shown in Table 2, the PCA affirmed the presence of five factors with eigenvalues exceeding 1, clarifying a total of 69.566 per cent of the variance and this was considered firm by Tabachnick and Fidell (2006), as well as Choi, Fuqua and Newman (2009).

Table 2

The Total Variance Explained ( $n=145)$

\begin{tabular}{|c|c|c|c|c|c|c|c|c|c|}
\hline \multirow[t]{2}{*}{ Factor } & \multicolumn{3}{|c|}{ Initial Eigenvalues } & \multicolumn{3}{|c|}{$\begin{array}{l}\text { Extraction Sums of Squared } \\
\text { Loadings }\end{array}$} & \multicolumn{3}{|c|}{$\begin{array}{c}\text { Rotation Sums of Squared } \\
\text { Loadings }\end{array}$} \\
\hline & Total & $\begin{array}{l}\% \text { of } \\
\text { Variance }\end{array}$ & $\begin{array}{c}\text { Cumulative } \\
\%\end{array}$ & Total & $\begin{array}{l}\% \text { of } \\
\text { Variance }\end{array}$ & $\begin{array}{c}\text { Cumulative } \\
\%\end{array}$ & Total & $\begin{array}{l}\% \text { of } \\
\text { Variance }\end{array}$ & $\begin{array}{c}\text { Cumulative } \\
\%\end{array}$ \\
\hline 1 & 16.313 & 52.622 & 52.622 & 16.313 & 52.622 & 52.622 & 6.315 & 20.371 & 20.371 \\
\hline 2 & 1.686 & 5.438 & 58.060 & 1.686 & 5.438 & 58.060 & 5.112 & 16.492 & 36.863 \\
\hline 3 & 1.355 & 4.371 & 62.430 & 1.355 & 4.371 & 62.430 & 4.448 & 14.348 & 51.211 \\
\hline 4 & 1.151 & 3.713 & 66.143 & 1.151 & 3.713 & 66.143 & 4.390 & 14.161 & 65.372 \\
\hline 5 & 1.061 & 3.423 & 69.566 & 1.061 & 3.423 & 69.566 & 1.300 & 4.195 & 69.566 \\
\hline
\end{tabular}

The Total Variance Explained $(n=145)$

All the items in this dimension have factor loadings ranging from .610 to .842 . Based on the factor analysis on Varimax rotation as shown in Table 3, the researcher may conclude that four out of the 
five factors were extracted according to each respective component, i.e., items POD2, POD5, POD6, FCC1, FCC2, FCC4, FCC5, FCC6 and PRL1 were loaded in Factor 1 (Fostering a Collaborative Culture), items FIES1, FIES3, FIES4, MLAS1 and MLAS3 were loaded in Factor 2 (Facilitating Improvement and Establishing Standards) which refers to Factor 1 in its original instrument, items FIES5, MLAS4, MLAS6 and MLAS7 were loaded in Factor 3 (Modeling Leadership Attributes and Skills) which refers to Factor 2 in its original instrument, and items PRL2, PRL3, PRL4, and PRL5 in Factor 4 (Performing as Referral Leader) which refers to Factor 5 in its original instrument. However, none of the factors were loaded in Factor 3, which refers to Participating in Organizational Development (POD) in its original instrument (Kho et al., 2015).

Meanwhile, three items (FCC3, PRL6, and PRL7) were cross loaded and had therefore been deleted. Furthermore, another three items (MLAS2, POD1, and POD4) were not loaded anywhere, which also implied that the items had zero factor loadings. Simply stated, only 22 out of the 31 items of the Teacher Leadership Competency Scale (TLCS) were extracted through Exploratory Factor Analysis (EFA) (Kho et al., 2015). The result showed that the factor loadings of the retained 22 items of the four factors were more than .6 (Zainudin Awang, 2012). It confirmed the high variation from .515 to .828 suggesting the high variance among the variables.

As the loading of the other two items (MLAS5, and POD3) was small $(<.5)$ it therefore, had less influence on the component score (Blunch, 2008). Hence, it was excluded from the rotated component matrix. In sum, a total of 22 items of the TLCS were retained for the final survey as illustrated in Table 3 .

Consequently, each loaded factor was assessed by Cronbach's alpha measure. As a rule of thumb, the acceptable Cronbach's alpha value was at least 0.7 (Hair et al., 2009). Indeed, Cronbach's alpha was .936 for Fostering a Collaborative Culture (FCC); .855 for Facilitating Improvement and Establishing Standards (FIES); .829 for Modeling Leadership Attributes and Skills (MLAS); and .844 for Performing as Referral Leader (PRL). 
Table 3

The Rotation Method of 'Varimax' for Teachers' Leadership Competencies Scale (TLCS) with Values of Consistence

\begin{tabular}{cccccc}
\hline Description of items & $h^{2}$ & 1 & 2 & 3 & 4 \\
\hline The teachers in my school are competent in: & & & & &
\end{tabular}

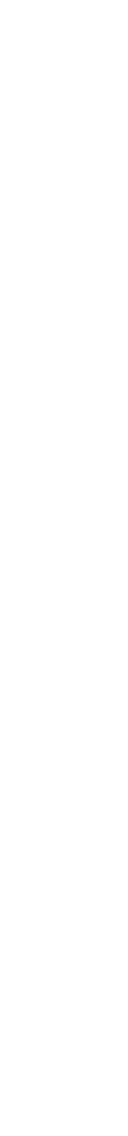

\section{Fostering a Collaborative Culture}

POD5 utilizing data to make informed decision

$.804 \quad .782$

FCC2 accessing and utilizing research data to improve $\quad \begin{array}{r}715 \\ .746\end{array}$ managerial practices

FCC4 making improvements in management practices $\quad \begin{array}{lll}.772 & .714\end{array}$ based on data analysis

FCC5 collaborating and sharing responsibilities with

641.673 others for student excellence

FCC6 practicing professional learning through research

FCC1 fostering teamwork in order to achieve targeted

.582 .663 goals

POD6 providing feedback to the management to enhance school improvement

PRL1 exemplifying ethical standards

POD3 developing the school's capacity for strategic development (vision and mission, professional development, infrastructure, finance, student activities, student achievement)

\section{Facilitating Improvement and Establishing Standards}

FIES3 practicing collaboration culture in order to maximize student performance

and meeting the needs of the students

FIES4 establishing standards for student behavior and school-wide classroom management policies

FIES1 modeling various leadership values and

FIES5 practicing life-long learning

MLAS3 nurturing the ability to make good decision among peers and students

\section{Modeling Leadership Attributes and Skills}

MLAS6 helping students to apply effective interpersonal .838 and intrapersonal communication skills 


\begin{tabular}{|c|c|c|c|c|c|c|}
\hline \multicolumn{2}{|r|}{ Description of items } & $h^{2}$ & 1 & 2 & 3 & 4 \\
\hline \multirow[t]{2}{*}{ MLAS4 } & $\begin{array}{l}\text { developing student potential for higher order } \\
\text { thinking and }\end{array}$ & .720 & & & .674 & \\
\hline & practicing life-long learning values & 683 & & & .649 & \\
\hline \multirow[t]{2}{*}{ MLAS1 } & $\begin{array}{l}\text { inculcating ethical/integrity values in leadership } \\
\text { practices }\end{array}$ & .654 & & & .654 & \\
\hline & Performing as Referral Leader & & & & & \\
\hline PRL4 & $\begin{array}{l}\text { dealing with instructional and management } \\
\text { matters }\end{array}$ & .788 & & & & .782 \\
\hline PRL5 & $\begin{array}{l}\text { demonstrating exemplary practices on "organi- } \\
\text { zational change and innovation" }\end{array}$ & .768 & & & & .762 \\
\hline PRL3 & $\begin{array}{l}\text { leading groups, workshops, collaborative work, } \\
\text { mentoring, teaching adults and action research }\end{array}$ & 671 & & & & .748 \\
\hline PRL2 & $\begin{array}{l}\text { contributing above and beyond their prescribed } \\
\text { roles }\end{array}$ & .457 & & & & .617 \\
\hline \multicolumn{2}{|c|}{ Eigenvalues } & & 14.13 & 1.50 & 1.28 & 1.04 \\
\hline \multicolumn{2}{|c|}{ Total Variance Explained } & & 22.00 & 16.36 & 14.28 & 13.92 \\
\hline \multicolumn{2}{|c|}{ \% Cumulative Variance Explained } & & 22.00 & 38.36 & 52.64 & 66.57 \\
\hline
\end{tabular}

Items $(n=145)$.

\section{The Assessment of the Pooled Measurement Model of the TLC Constructs}

After producing a very good fit of the Pooled Measurement Model based on First Order CFA which indicates the presence of four latent variables, namely Fostering a Collaborative Culture (FCC), Facilitating Improvement and Establishing Standards for Students Behavior (FIES), Modeling Leadership Attributes and Skills (MLAS), and Performing as Referral Leader (PRL) which was measured by nine observed variables for (FCC), five observed variables for FIES, and four observed variables for MLAS and PRL respectively. Thus, using the rule of thumb of at least three indicators per construct, but promoting a minimum of four as proposed by Hair et al. (2006), the proposed model for the Teacher Leadership Competency (TLC) was accomplished.

Nonetheless, since FIES1 (Modeling various leadership values and behavior) has a very low factor loading (.47), it is a very good candidate to be eliminated as it did not meet the threshold of .50 for significant factor loading (Byrne, 2010; Hair, et al., 2010). The Root-Mean Square Error of Approximation (RMSEA) of .053 also 
surpassed the .08 suggested cut off value. All the GFI (.931), AGFI (.914), CFI (.959), TLI (.953) and NFI (.944) goodness-of-fit indices also surpassed the threshold value of .90 , specifying a very good fit. The Normed Chi-Square $\left(\chi^{2}\right)$ which is the chi-square value divided by the degree of freedom (721.512/203) was 3.554 indicating acceptable fit of the model. According to Hair et al. (2006) and Byrne (1989), a number smaller than 2.0 is considered a good fit, whereas the range between 2.0 and 5.0 is acceptable for model fit (Marsh \& Hocevar, 1985). Thus, construct validity of the model is achieved.

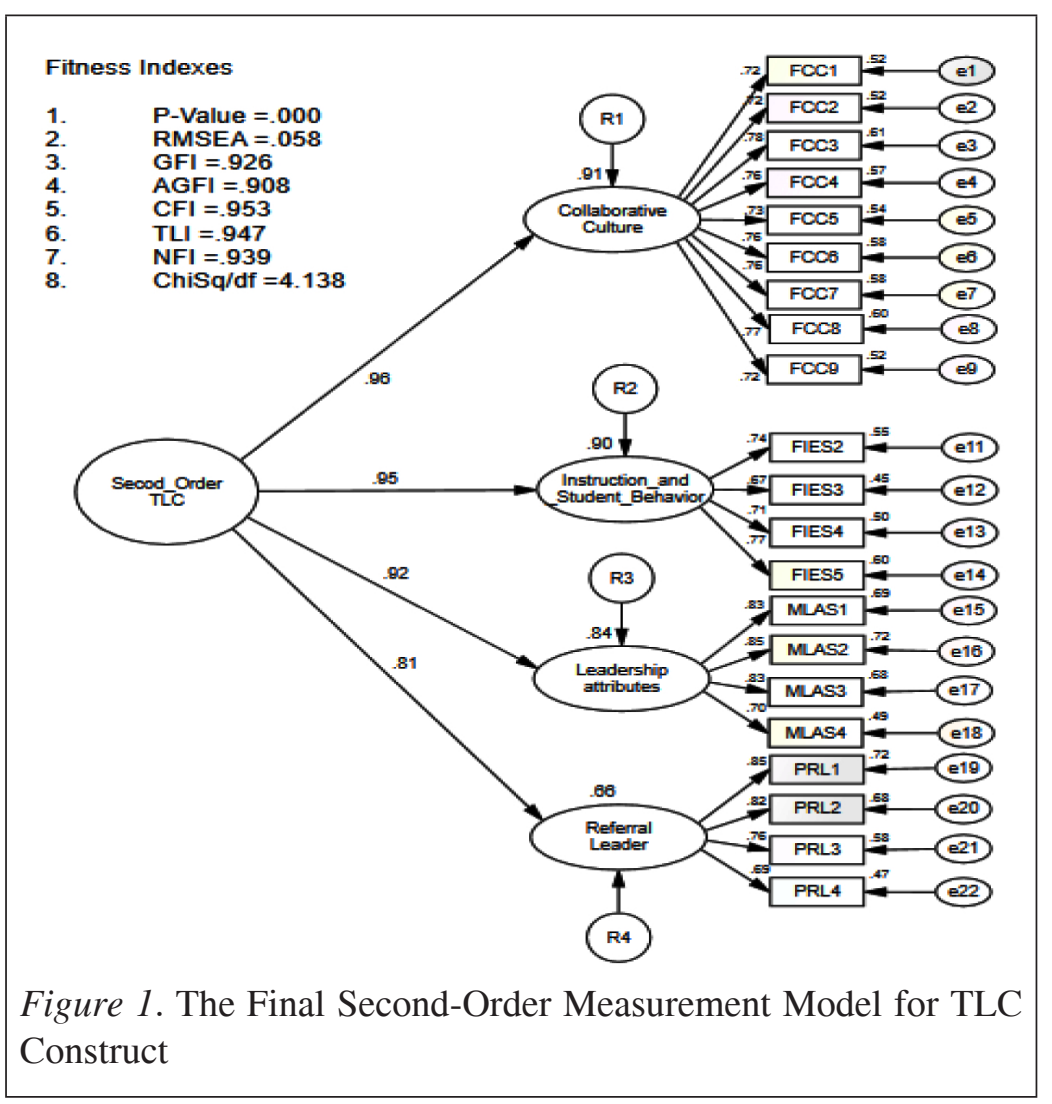

Similarly, the result of the first-order CFA supported a good fit measurement model for the TLC constructs. Thus, it brought to attention the need to assess the TLC at a higher level. Due to this, two stages of a second-order CFA; the initial and final stages of the TLC Measurement Model were performed. The result of the initial 
second order CFA indicated that the factor loading of FIES1 (.46) was extremely low for the newly developed item. According to Hair et al. (1995, 2010) and Holmes-Smith (2006), the factor loading for a newly developed item should be 0.5 or higher. Thus, FIES1 was eliminated during the final second-order CFA after taking into consideration the practicability based on experience and literature, by which in most cases the ethical or integrity values of a leader was hardly assessed in leadership practice (Figure 1). In fact, leadership practice should be ethical as it was a responsibility not just to be personally moral, but also to provide 'civic moral education' that would lead to both self-knowledge and community awareness as well (Foster, 1989). This result again confirmed that the TLC model was measured by the items adequately well.

\section{Convergent Validity}

To assess the convergent validity, the researchers examined the Average Variance Extracted (AVE) of the model (Table 4). The analysis indicated that all the items satisfied the cut-off value of.50, which also meant that all the items met the required value of convergent validity. The factor loading was also statistically significant (Holmes-Smith, 2001). Finally, the researcher evaluated the construct reliability (CR) of the TLCS (Table 4). The high $\mathrm{CR}$ indicated that internal consistency existed, which meant that all the measures consistently represented the same latent construct (Hair et al., 2006).

Table 4

The CFA Reporting for the TLC Measurement Model

\begin{tabular}{ccccc}
\hline Construct & Item & Factor Loading & $\begin{array}{c}\text { CR } \\
\text { (above 0.6) }\end{array}$ & $\begin{array}{c}\text { AVE } \\
\text { (above 0.5) }\end{array}$ \\
\hline \multirow{2}{*}{ TLC } & Collaborative Culture & .96 & $\mathbf{. 9 5 2}$ & $\mathbf{. 8 3 2}$ \\
& Instruction \& Student & .95 & & \\
Behavior & & & \\
& Leadership Attribute & .92 & & \\
& Referral Leader & .81 & & \\
& & & \\
\hline
\end{tabular}

(continued) 


\begin{tabular}{|c|c|c|c|c|}
\hline Construct & Item & Factor Loading & $\begin{array}{c}\text { CR } \\
\text { (above 0.6) }\end{array}$ & $\begin{array}{c}\text { AVE } \\
\text { (above 0.5) }\end{array}$ \\
\hline \multirow{9}{*}{$\begin{array}{l}\text { Collaborative } \\
\text { Culture }\end{array}$} & FCC1 & .72 & .900 & .563 \\
\hline & $\mathrm{FCC} 2$ & .72 & & \\
\hline & $\mathrm{FCC} 3$ & .78 & & \\
\hline & $\mathrm{FCC} 4$ & .78 & & \\
\hline & FCC5 & .73 & & \\
\hline & FCC6 & .76 & & \\
\hline & FCC7 & .76 & & \\
\hline & FCC8 & .77 & & \\
\hline & FCC9 & .72 & & \\
\hline \multirow{4}{*}{$\begin{array}{l}\text { Instruction } \\
\& \text { Student } \\
\text { Behavior }\end{array}$} & FIES2 & .74 & .857 & .600 \\
\hline & FIES3 & .87 & & \\
\hline & FIES4 & .71 & & \\
\hline & FIES5 & .77 & & \\
\hline \multirow{4}{*}{$\begin{array}{l}\text { Leadership } \\
\text { Attribute }\end{array}$} & MLAS1 & .83 & .880 & .648 \\
\hline & MLAS2 & .85 & & \\
\hline & MLAS3 & .83 & & \\
\hline & MLAS4 & .70 & & \\
\hline \multirow[t]{4}{*}{ Referral Leader } & PRL1 & .85 & .904 & .703 \\
\hline & PRL2 & .82 & & \\
\hline & PRL3 & .79 & & \\
\hline & PRL4 & .89 & & \\
\hline
\end{tabular}

\section{Discriminant Validity}

Since constructs of the TLC, i.e., Fostering a Collaborative Culture (FCC), Facilitating Improvement and Establishing Standards for Student Behavior (FIES), Modeling Leadership Attributes and Skills (MLAS), and Performing as Referral Leader are highly correlated, the researcher decided to test the competing models of Principals' Developmental Leadership Behavior (PDLB) and Teacher Commitment to Change (TCC) for discriminant validity. Table 5 showed that the diagonal value (in bold) are higher than any other values in its row and column. Thus, the discriminant validity for the TLC-PDLB-TCC constructs was achieved. 
Table 5

The Discriminant Validity Index Summary

\begin{tabular}{cccc}
\hline Construct & TLCM & PDLBM & TCCM \\
\hline TLCM & sqrt $(.822)$ & & \\
PDLBM & 0.65 & sqrt $(.848)$ & \\
TCCM & 0.81 & 0.74 & $\operatorname{sqrt~(.941)}$ \\
\hline
\end{tabular}

\section{RESULTS}

The finding for the first teacher leadership competency - 'Fostering a Collaborative Culture', was in line with the notion found in the studies, namely the Teacher Leader Model Standards (TLEC, 2011), Danielson's Framework for Teaching Evaluation Instrument (2013), Teacher Leadership Skills Framework (CSTP, 2009), and Teachers as Leaders Framework (2008), which conveyed the same message about the need to collaborate with others and the importance of fostering a 'collaborative culture', which in turn, promoted meaningful change in student achievement and school improvement. Hence, teachers should enroll themselves as members of any professional learning community promoting teacher leadership (Barth, 2001). Indeed, teachers in schools, in one way or another should take responsibility as leaders (Goleman, Bryatzis, \& McKee, 2002).

Next, the finding for the second teacher leadership competency - 'Facilitating Improvement and Establishing Standards' was peculiarly aligned to the fourth domain of the Teacher Leader Model Standards (TLEC, 2011) - 'Facilitating Improvements in Instruction and Student Learning' which focused on the knowledge base needed by a teacher leader in order to meet the performance expectations for school reform. Besides, the third domain in the Teachers as Leaders Framework (2008) - 'Strive for pedagogical excellence' also highlighted the importance of facilitating improvement in instruction and establishing positive student behavior through indicators such as: i) showing genuine interest in student needs and well-being; ii) continuously developing and refining personal teaching gifts and talents; and iii) seeking deep understanding of significant pedagogical practices. 
The finding for the third teacher leadership competency - 'Modeling Leadership Attributes and Skills' was peculiarly aligned to the second domain of the Framework for Teaching Evaluation Instrument (Danielson, 2013) - 'The Classroom Environment' which focused on caring interactions among teachers and students and positive and respectful interactions among students for healthy school environment. For this purpose, teacher leaders should inculcate integrity values among students to enhance their leadership skills. Besides, teacher leaders not only model and teach students positive ways to engage in respectful interactions with one another, but also acknowledge such interactions to make school reform happen.

Lastly, 'Performing as Referral Leader' was identified as the fourth teacher leadership competency. The finding was congruent with the 'Teacher Leader Differentiators' - 'Lead by Example' in the Teacher Leader Model Standards (TLEC, 2011). Although, the finding also revealed that 'Performing as Referral Leader' (.81) was the least dominant factor compared with 'Fostering a Collaborative Culture' (.96), Facilitating Improvement and Establishing Standards (.95), and 'Modeling Leadership Attributes and Skills' (.92) (Figure 1 ), it was not an unpredicted role for teachers to assume leadership roles as referral leader as it had been clearly identified in the fourth domain of the Framework For Teaching Evaluation Instrument (Danielson. 2013) - 'Professional Responsibilities' particularly in the 4e component: 'Growing and Developing Professionally' which encouraged teacher leaders to continuously stay informed and increase their leadership skills. Activities such as joint planning, study groups, and lesson study provided opportunities for teacher leaders to exercise their leadership skills effectively. Likewise, effective teacher leaders were able to enhance both their personal practice and their ability to provide leadership and support to colleagues to realize the schools' reform goals.

\section{DISCUSSION AND DIRECTIONS FOR FUTURE RESEARCH}

First, as teachers had the potential to practice new and dynamic leadership roles in schools (Katzenmeyer \& Moller, 1996, 2009), they would begin to believe in their leadership capabilities, as such 
community development via teacher leadership was needed (Barth, 2001). The data utilized in this study were based on the development of teacher leadership competencies based on four distinct leadership competencies that had been practiced in the respective Malaysian high performing secondary schools. To strengthen the validity of the findings, it would therefore be worthwhile to examine the development of teacher leadership that had been informally initiated at the same time by all the schools involved in the research so as to make the teacher leadership studied more comparable.

Second, as the TLCM was developed solely based on the perception of leadership practices, to gain a balanced and comprehensive view, as well as to increase the ability to interpret the findings, further research is recommended to involve teacher leaders and senior assistants so as to gain a multidimensional perspective of the phenomenon. In addition, as Pitman (2008) had pointed out, teacher perception on leadership practices was often explored differently in distinct school contexts, future research across schools should be conducted too for a better understanding of the interrelated nature of structural supports to develop teacher leadership capacity and thus, the validity of the model.

Third, by focusing only on the HPSS, the researcher could easily and more accurately identify the most critical components of the TLC. Similar research could be pursued on a more diverse sample, so as to test the validity of the study's model across different samples and the extent to which the results of the study could be generalised.

\section{CONCLUSION}

The development and validation of the Teacher Leadership Competency Scale (TLCS) would contribute to a better scholarly understanding and provide a fresh look at teacher leadership, particularly in planning and designing training programmes for teacher leaders in Malaysian schools. It would also provide the much needed direction for practitioners in the development of a Teacher Education Model for Malaysia. Obviously, only those most critical leadership competencies that emerged were important factors in the model. If teacher leaders are able to focus on the most critical 
leadership competencies, namely i) Fostering a Collaborative Culture, ii) Facilitating Improvements and Establishing Standards, iii) Modeling Leadership Attributes and Skills, and iv) Performing as Referral Leader (Figure 1), there is little doubt that most critical competencies of leadership as a driving force can be fine-tuned for greater efficiency and greater potential contribution to school reform (Tubbs \& Schulz, 2006). Leadership competencies also contribute to teacher professionalism in ensuring successful change in school reform initiated by the teachers themselves (Sharifah Nor Puteh \& Aliza Ali, 2013). Yamazaki and Kayes (2004) as well as Yaakob Daud and Yahya Don (2012), also pointed out that identifying leadership competencies in the current school scenario were also very valuable input in transforming leadership practices in schools. Hence, the newly developed TLCS is a significant step in delineating teacher leadership competencies which were very much needed in teacher leadership practices in schools, districts, and the profession.

\section{ACKNOWLEDGEMENT}

This study is part of the Development of the Teacher Education Model for Malaysia, led by Professor Dato' Dr. Noraini Idris, through a grant from the Sultan Idris Education University (UPSI) and the Ministry of Higher Education under the Niche Research Grant Scheme (NRGS). The work on this study was also supported by other research team members from the project on Teacher Leadership.

\section{REFERENCES}

Abdulhakam Hengpiya (2008). Construct validation of a school principal decision-making styles scale. Malaysian Journal of Learning and Instruction, 5, 41-61.

Andrews, D., Crowther, F., Hann, L., \& McMaster, J. (2002). Teachers as leaders: Re-imaging the profession. The Practising Administrator, 1.

Barth, R. (2001). Learning by heart. San Francisco: Jossey-Bass. Barth, R. S. (2001). Teacher leader. Phi Delta Kappan, 82(6), 443-449. 
Baruch, Y.,\& Holtom, B.C. (2008). Survey response rate levels and trends in organizational research. Human Relations, 61, 11391160.

Blunch, N. J. (2008). Introduction to structural equation modeling using SPSS and AMOS. London: Sage.

Bowen, J., \& Shoemaker, S. (1998). Loyalty: a strategic commitment. Cornell and Restaurant and Administration Quarterly, 39, 12-25.

Byrne, B. M. (1989). A primer of LISREL: Basic applications and programming for confirmatory factor analytic models. New York, NY: Springer-Verlag.

Byrne, B. M. (2001). Structural equation modeling with Amos: Basic concepts, applications, and programming. Mahwah, NJ: Erlbaum.

Byrne, N. M. (2010). Structural equation modeling with AMOS: Basic concepts, applications, and programming (2nd ed.). New York, NY: Taylor and Francis Group.

Centre for Strengthening the Teaching Profession (2009). Teacher leadership skills framework. Retrieved from http://www.cstpwa.org.

Chesterton, P., \& Duignan, P. (2004). Evaluation of the national trial of the IDEAS Project, Report to DEST March.

Choi, N., Fuqua, D.R., \& Newman, J.L. (2009). Exploratory and confirmatory studies of the structure of the bem sex role inventory short from with two divergent samples. Educational and Psychological Measurement, 9(4), 696-705.

Chua, Y. P. (2009). Statistik penyelidikan lanjutan: Ujian regresi, analisis faktor dan analisis SEM. [Advanced Statistics: Regression Test, Factor Analysis and SEM Analysis]. Kuala Lumpur: McGraw-Hill.

Churchill, G. A. (1995). Marketing research methodological foundation (6th ed.). Orlando, Florida: The Dryden Press.

Creswell, J. W. (2005). Educational research: Planning, conducting and evaluating Quantitative and qualitative research (2nd ed.). Upper Saddle River, N. J.: Pearson Merrill Prentice Hall.

Cronbach, L. J. (1951). Coefficient alpha and the internal structure of tests. Psychometrika, 16(3), 297-334.

Crowther, F., Kaagan, S., Ferguson, M., \& Hann, L. (2002a). Developing teacher leaders: How teacher leadership enhances school success. California: Sage Publications. 
Crowther, F., Hann, L., \& Andrews, D. (2002b). Rethinking the role of the school principal: Successful school improvement in the postindustrial era. Australia: The Practicing Administrator.

Crowther, F. (2008). Teachers as leaders framework. Retrieved from http://www.corwin.com/upm-data/25560_1204_Crowther_ Ch_1_excerpt.pdf.

Danielson, C. (2013). The framework for teaching evaluation instrument. Retrieved from http://www.frame work for teachingevaluationinstrument.org/downloads/TLS_Brochur_ sm.pdf

Elmore, R. E. (2000). Building a new structure for school leadership. Winter:The Albert Shanker Institute.

Fink, A. (2006). How to Conduct Surveys: A Step-by-Step Guide (3rd ed.). Sage Publication.

Flowers, C. (2006). Confirmatory factor analysis of scores on the clinical experience rubric: A measure of dispositions for preservice teachers. Educational and Psychological Measurement, 66(3), 478-488.

Foster, L. A. (1989). Breaking down racial isolation. Educational Leadership, 47(2), 76-77.

Frazer, L., \& Lawley, M. (2000). Questionnaire design \& administration: a practical guide. Brisbane: John Wiley \& Sons Australia, Ltd.

Fullan, M. (2010). The moral imperative realized. Thousand Oaks, CA: Corwin Press.

Goleman, D., Boyatzis, R., \& McKee, A. (2002). Primal leadership: Realizing the power of emotional intelligence. Boston: Harvard Business School Press.

Harris, A. (2002). Distributed leadership in schools: Leading or misleading. Keynote paper presented at the BELMAS annual conference, Aston University Lakeside Conference Centre, Birmingham, England.

Hair J. F., Anderson, R. E., Tatham, R. L., \& Black, W. C. (1995). Multivariate data analysis with readings (4th ed.). Eaglewood Cliffs, NJ: Prentice Hall.

Hair, J. F., Anderson, R. E., Tatham, R. L., \& Black, W. C. (2006). Multivariate data analysis (5th ed.). New Jersey: Prentice Hall. Hair, J. F., Black, W. C., Babin, B. J., Anderson, R. E., \& Tatham, R. I. (2009). Analise multivariada de dados (6th ed.). Porto Alegre, RS: Bookman. 
Hair, J. F ., Black, W. C., Babin, B. J., \& Anderson, R. E. (2010). Multivariate data analysis: A global Perspective (7th ed.). Upper Sadle River: Pearson Prentice Hall.

Heschel, A. J. (1962). The Prophets. New York: Harper Row. Holmes-Smith, P. (2001). Introduction to structural equation modeling using LISREAL. Perth: ACSPRI-Winter Training Program.

Holmes-Smith, P. (2006). School socio-economic density and its effect on school performance. Report prepared for the New South Wales Department of Education and Training.

Johnson, B., \& Christensen, I. (2008). Educational research: Quantitative, qualitative, and mixed approaches. Thousand Oaks, CA: Sage Publications.

Kaiser, H. (1970). A second generation Little Jiffy. Psychometrica, 35(4), 401-415.

Kaiser, H. (1974). An index of factorial simplicity. Psychometrica, 39(1), 31-36.

Katyal, K.R.,\& Evers, C.W. (2004). Teacher leadership and autonomous student learning: Adjusting to the new realities. International Journal of Educational Research, 41, 367-382. Katzenmeyer, M.,\& Moller, G. (1996). Awakening the sleeping giant: Leadership development for teachers. Thousand Oaks, CA: Corwin Press.

Katzenmeyer, M.,\& Moller, G. (2009). Awakening the sleeping giant: Helping teachers develop as leaders (3rd ed.). Thousand Oaks, CA: Corwin Press.

Kementerian Pendidikan Malaysia (2014). Institut Pendidikan Guru Malaysia. Kuala Lumpur: Kementerian Pendidikan Malaysia.

Kho, F. C. Y., Hamidah Yusof, \& Syed Ismail Syed Mohamad (2014). Confirmatory factor analysis of the niche-Malaysian teacher leadership measurement model. International Journal for Innovation Education and Research, 2(07), 1-10.

Kho, F. C. Y., Hamidah Yusof, \& Syed Ismail Syed Mohamad (2015). The power of leadership for learning: Developing niche-Malaysian Teachers' leadership competency model. Paper presented at the International Conference on Accounting Studies, Johor Bahru, Malaysia.

Kho, F. C. Y., Hamidah Yusof, \& Syed Ismail Syed Mohamad (2015a). A confirmatory factor analysis of the nicheMalaysian teacher leadership competency instrument (NMTLCI). Australian Journal of Basic and Applied Science, 9(25), 125-133. 
Kline, R. B. (2005). Principles and practice of structural equation modeling (2nd ed.). New York, NY: Guilford.

Knapp, M. S., Copland, M. A., Ford, B., Markholt, A., McLaughlin, M.W., Milliken, M., \& Talbert, J. E. (2003). Leading for learning sourcebook: Concepts and examples. Center for the Study of Teaching and Policy. Seattle, WA: University of Washington.

Lashway, L. (2003). Distributed leadership. Research Roundup 19(4), Summer. Available: http://eric.uoregon.edu/publications/ roundup/ Summer_2003.html

MacBeath, J. (2012). Leadership for learning. The Cambridge Network, 2, 1-9.

Mahaliza Mansor, Norlia Mat Norwani, \& Shahril @ Charil Marzuki. (2011). Validity and reliability of the school-based professional development leader roles inventory. Management Research Journal, 1(1), 73-87.

Marsh, H.W., \& Hocevar, D. (1985). Application of confirmatory factor analysis to the study of self-concepts: First- and higherorder factor-models and their invariance across groups. Psychological Bulletin, 97, 562-582.

Netemeyer, R. G., Bearden, W. O., \& Sharma, S. (2003). Scaling procedures: Issues and applications. Thousand Oaks, CA: Sage Publications.

Neuman, W. L. (2006). Social research methods: Qualitative and quantitative approaches (6thed.). Boston: Pearson Education Inc.

Nor Asma Sheirnawani Abdul Rahman, Mohd Asri Mohd Noor, Rohaila Yusof, \& Hamidah Yusof (2015). Kesahan model amalan kepimpinan guru. Jurnal Kurikulum \& Pengajaran Asia Pasifik, 3(2), 1-11.

Norazlinda Saad, \& Surendran Sankaran. (2013). The effects of teachers' attitude towards decisions making on teachers' commitment in school: Principals' support as a mediator. Malaysian Journal of Learning and Instruction, 10, 271-294.

Patton, M. Q. (2002). Qualitative evaluation and research methods (2nd ed.). Newbury Park, CA: Sage.

Pearce, C. L., \& Sims, H. P. (2002). Vertical versus shared leadership as predictors of the effectiveness of change management and teams: An examination of aversive, directive, transactional, transformational and empowering leader behaviors. Group Dynamics: Theory, Research, and Practice, 6(2), 172-197. 
Popper, K. R. (1970). Normal science and its dangers. In I. Lakatos., \& A. Musgrave (Eds.), Criticism and growth of knowledge. New York: Cambridge University Press.

Salciuviene, L., Auruskeviciene V., \& Lydeka, Z. (2005). An assessment of various approaches for cross-cultural consumer research. Problems and Perspectives in Management, 3, 147-159.

Saunders, M., Lewis, P.,\& Thornhill, A. (1997). Research methods for business students. London: Pitman.

Sekaran, U. (2000). Research methods for business: A skill-building approach (3rd ed.). New York, NY: John Wiley \& Sons.

Sekaran, U. (2003). Research methods for business (4th ed.). Hoboken, NJ: John Wiley \& Sons.

Sharifah Nor Puteh, \& Aliza Ali (2013). Preschool teachers' perceptions towards the use of play-based approach in language and literacy development for preschool. Malaysian Journal of Learning and Instruction, 10, 79-98.

Silins, H., \& Mulford, B. (2002). Leadership and school results, In K. Leithwood \& P. Hallinger (Eds). International handbook of educational leadership and administration. Kluwer, Norwell MA, pp 561-612.

Spillane, J. P. (2006). Distributed leadership. San Francisco: JosseyBass.

Spillane, J. P., Halverson, R., \& Diamond, J. B. (2001). Investigating school leadership practice: A distributed perspective. Educational Researcher, April, 23-28.

Tabachnick, B.G.,\& Fidell, L.S. (2006). Using multivariate statistics (5th ed.) New York: Allyn \& Bacon.

Teacher Leadership Exploratory Consortium. Teacher Leader Model Standards. (2011). Retrieved from http://www. teacherleaderstandards.org/downloas/TLS_Brochure_sm.pdf

Tubbs, S.L.,\& Schulz, E. (2006). Exploring a taxonomy of global leadership competencies and meta-competencies. The Journal of American Academy of Business, 8(2), 35-47.

Yaacob Daud, \& Yahya Don (2012). School Cultures, Transformational leadership and students' academic achievement. Malaysian Journal of Learning and Instruction, 9, 111-139.

Yamazaki, Y., \& Kayes, D. C. (2004). An experimental approach to cross-cultural learning: A review and integration of competencies for successful expatriate adaptation. Academy of Management Learning and Education, 3(4), 362-379. 
Zainudin Awang (2012). Research methodology and data analysis (2nd ed.). Shah Alam: Universiti Teknologi MARA Publication Centre (UiTM Press). 